\title{
The Impact of Inulin and a Novel Synbiotic (Yeast Saccharomyces cerevisiae Strain 1026 and Inulin) on the Development and Functional State of the Gastrointestinal Canal of Calves
}

\author{
S. Jonova $\mathbb{D}^{1},{ }^{1}$ A. Ilgaza, ${ }^{1}$ and $M$. Zolovs $\mathbb{D}^{2}$ \\ ${ }^{1}$ Latvia University of Life Sciences and Technologies, Faculty of Veterinary Medicine, Preclinical Institute, Helmana Iela 8, \\ Jelgava, LV-3004, Latvia \\ ${ }^{2}$ Daugavpils University, Institute of Life Sciences and Technology, Department of Biosystematics, Parades Iela 1a, Daugavpils, \\ LV-5401, Latvia \\ Correspondence should be addressed to S. Jonova; sintija.jonova@llu.lv
}

Received 5 August 2020; Revised 8 December 2020; Accepted 26 December 2020; Published 6 January 2021

Academic Editor: Arnab Sen

Copyright (c) $2021 \mathrm{~S}$. Jonova et al. This is an open access article distributed under the Creative Commons Attribution License, which permits unrestricted use, distribution, and reproduction in any medium, provided the original work is properly cited.

\begin{abstract}
Successful management of the dairy industry is closely related to rearing healthy calves. The proper development of the gastrointestinal canal is crucial to reach this goal. One of the strategies to promote this development is the addition of feed additives to the diet. This research aimed to determine the impact of prebiotic inulin and a new, not commercially available synbiotic (mix of prebiotic inulin and probiotic $S$. cerevisiae strain 1026) on the development of the gastrointestinal canal of calves by comparing the weight of the stomach, its relative ratio to body weight and evaluating $\mathrm{pH}$, and histological changes in different parts of the gastrointestinal canal and assess whether or not the addition of inulin to the yeast $S$. cerevisiae improves the abovementioned parameters. We used prebiotic inulin $(6 \mathrm{~g})$ and a synbiotic (prebiotic inulin $6 \mathrm{~g}$ and probiotic Saccharomyces cerevisiae strain 1026 , $5 \mathrm{~g}$ ). The 56-day long research was conducted with fifteen crossbreed calves ( $32 \pm 6$ days old) organized in the control group $(\mathrm{CoG})$, the prebiotic group (PreG), and the synbiotic group (SynG). We determined $\mathrm{pH}$, morphological parameters of different parts of the digestive canal, and morphometric parameters of the stomach. The addition of prebiotic inulin to calves' diet causes the increase of $\mathrm{pH}$ in rumen, abomasum, and intestines but when inulin was added to S. cerevisiae, $\mathrm{pH}$ decreased and was even lower than in the control group. Prebiotic inulin and its synbiotic with yeast $S$. cerevisiae positively impact the development of almost all morphological structures of rumen saccus dorsalis, rumen saccus ventralis, and intestine; moreover, calves from the synbiotic group showed better results in virtually all parameters. However, both inulin and synbiotic did not affect the weight and relative weight of different parts of the stomach. Tested synbiotic has the potential to promote the development of the rumen and other parts of the digestive canal of calves.
\end{abstract}

\section{Introduction}

Raising healthy calves in the dairy industry is essential as it directly impacts their development and future quality and quantity of produced milk. The proper development of the gastrointestinal canal is crucial to reach this goal. The rumen is an essential organ of the gastrointestinal canal that plays a major role in the growth and development of ruminants. At birth, the rumen is not fully developed, and it takes some time for it to start functionating at the level of adult ruminants. The specific changes happen in the rumen, including the development of rumen epithelium and the establishing of rumen microbiota [1]. The rumen only starts to grow at two to three weeks of age, and its growth will continue until about six months of age [2]. At birth, the weights of reticulorumen, omasum, and abomasum account for $38 \%, 13 \%$, and $49 \%$ of the whole stomach weight, respectively. At 12 to 16 weeks of age, they reach $67 \%, 18 \%$, and $15 \%$ of the stomach weight, respectively [1]. The abomasum is the only compartment of the whole stomach that is fully developed in newborn calves. Later on, the rumen begins to develop and starts to play a more important role in 
digestive processes. A rumen is well developed if the number of papillae and their size have greatly increased, so the total absorption surface is bigger and more nutrients can be absorbed [3]. The epithelium of rumen has many vital functions, and it plays a key role in rumen development, including absorption of nutrients, their transportation to other parts of the body, metabolism of short-chain fatty acids, and protection of rumen. The growth and proliferation of the rumen squamous epithelium contribute to the growth of papillae length and width and increase the thickness of the whole rumen wall [4]. The papillae length and width are the most important factors for the evaluation of rumen [5].

A lot of strategies describe how to promote the development of the morphological structure and metabolic function of the rumen and other parts of the gastrointestinal canal in calves and one of them is the addition of different feed additives to the diet such as probiotics and synbiotics. A wide variety of feed additives used for calves are available on the market. In 2008, the $6^{\text {th }}$ Meeting of the International Scientific Association of Probiotics and Prebiotics (ISAPP) defined "dietary prebiotics" as "a selectively fermented ingredient that results in specific changes in the composition and/or activity of the gastrointestinal microbiota, thus conferring benefit(s) upon host health" [6]. Probiotics are viable and beneficial microorganisms that help maintain microbial balance in the gastrointestinal canal and promote rumen development [7, 8]. For example, probiotic yeast Saccharomyces cerevisiae (S. cerevisiae) positively impacts ruminal microbiota by increasing rumen total bacteria, fungi, and protozoa [9] and improving ruminal morphology $[10,11]$. Saccharomyces cerevisiae provides growth factors, including organic acids, $\mathrm{B}$ vitamins, and amino acids that stimulate microbial growth in the rumen, indirectly stabilizing ruminal $\mathrm{pH}$ [12]. Unlike probiotics, prebiotics act as a "food" for the target microbes with beneficial consequences for a host [13]. Prebiotics are resistant to gastric acidity, absorption, and hydrolysis by enzymes produced in the gastrointestinal canal [14]. The fermentation products of prebiotics by intestinal microflora also provide benefit by decreasing intestinal $\mathrm{pH}$, which suppresses pathogenic bacteria $[15,16]$. There are a lot of different types of prebiotics used in the livestock industry, such as fructooligosaccharides (FOS), galactooligosaccharides (GOS), mannan oligosaccharides (MOS), beta-glucans, inulin, and lactulose $[17,18]$. Inulin is a polysaccharide consisting of fructose joined by a $\beta 2,1$ glycosidic bond containing small amounts of glucose [19]. Inulin belongs to a class of carbohydrates known as fructans. The primary sources of inulin are chicory (Cichorium intybus L.) and Jerusalem artichoke (Helianthus tuberosus L.) [20]. Inulin is not digested and absorbed in the small intestine but is selectively and quickly fermented by bacteria in lower parts of the gastrointestinal canal, stimulating proliferation of different Lactobacillus, mainly Bifidobacterium. Inulin has a beneficial effect on metabolism. It nourishes intestinal cells and lowers intestinal $\mathrm{pH}$ and stimulates the lengthening of intestinal villi as well as an increasing number of epithelial cells in individual villus [19]. Synbiotics are defined as "a mixture, comprising live microorganisms and substrate(s) selectively utilized by host microorganisms, that confers a health benefit on the host" [21]. The combination of a probiotic and a prebiotic can have a synergistic beneficial effect. The combination of two feed additives can improve the survival and the implantation of a direct-fed microbial in the gastrointestinal canal and stimulate the growth and activate the metabolism of a limited number of beneficial bacteria [22].

This research aimed to determine the impact of prebiotic inulin and a new, not commercially available synbiotic (mix of prebiotic inulin and probiotic S. cerevisiae) on the development of the gastrointestinal canal of calves by comparing the weight of the stomach and its relative ratio to body weight and evaluating $\mathrm{pH}$ and histological changes in different parts of the gastrointestinal canal, as well as assessing whether or not the addition of inulin to the yeast $S$. cerevisiae improves the abovementioned parameters.

\section{Materials and Methods}

2.1. Ethical Approval. All procedures performed in studies involving animals were in accordance with the ethical standards. Research Committee of the Faculty of Veterinary Medicine, Latvia University of Life Sciences and Technologies, approved this study (protocol no. 2017/2).

2.2. Study Area and Experimental Design. The study was completed from March till the end of April 2018 on a dairy farm which is located in Jaunlutrini Parish (latitude: $\mathrm{N}$ $56^{\circ} 49^{\prime} 42.2^{\prime \prime}$, longitude: E $22^{\circ} 24^{\prime} 21.8^{\prime \prime}$ ), Latvia. Fifteen clinically healthy randomly selected Holstein Friesian and Red Holstein (Bos Taurus L.) crossbreed calves of mean age of $32 \pm 6$ days and initial body weight of $72.1 \pm 11.34 \mathrm{~kg}$ were used in the research. All calves were housed in groups in a partly closed space in a farm. After the birth, all calves received colostrum, and, for the next five days, calves received whole milk (3.51 twice a day) and later the milk replacer in a dosage appropriate to the age and weight of the calves. Calves from four to eight weeks of age received eight litres of milk replacer per calf/day and a prestarter without restriction (around $0.5 \mathrm{~kg}$ per calf/day). From eight weeks of age, they received approximately $1.5 \mathrm{~kg}$ of barley flour per calf/day, six litres of milk replacer per calf/day. All the time, calves were given access to hay and water ad libitum. Calves were allocated into three groups: five calves in the control group $(\mathrm{CoG})$ receiving a standard diet, five calves in the prebiotic group (PreG) that additionally received $12 \mathrm{~g}$ of flour of Jerusalem artichoke (Helianthus tuberosus L.) per head (50\% of which or $6 \mathrm{~g}$ is prebiotic inulin) (produced in Latvia at the University of Latvia Institute of Microbiology and Biotechnology), and five calves in the experimental group (SynG) that additionally received synbiotic- $12 \mathrm{~g}$ of flour of Jerusalem artichoke (Helianthus tuberosus L.) per head containing $6 \mathrm{~g}$ of prebiotic inulin and $5 \mathrm{~g}$ of probiotic Saccharomyces cerevisiae strain 1026 (Yea-Sacc ${ }^{\circledR}$, Alltech Inc, USA). The prebiotic and probiotic were added to barley flour once a day in the morning. The duration of the experiment was eight weeks (56 days). 
2.3. Sampling and Examination. At the end of the experiment, three calves from each group were slaughtered at a certified slaughterhouse following all guidelines of humane slaughter. We measured the $\mathrm{pH}$ of different parts of the digestive canal (mouth, rumen atrium ruminis, rumen ventral sac, abomasum close to the pyloric sphincter, the middle part of the abomasum, jejunum, and colon) by using portable meter ProfiLine $\mathrm{pH}$ 3110, Xylem Inc. and determined morphometric parameters of the stomach (total weight of empty stomach, the weight of abomasum and forestomachs, the relative weight of the whole stomach, forestomachs, and abomasum comparing to live weight). The histological examination of different samples obtained from the gastrointestinal canal was performed. Measurements of the length and the width of rumen papillae; the thickness of rumen epithelium; the thickness of abomasum mucosa in cardiac, fundus, and pyloric gland zones; and the thickness of mucosa and the whole wall of duodenum, jejunum, ileum, and crypt depth of colon were performed by using microscope Leica DM 750, Leica Microsystems and software Leica Application Suite, and Leica Microsystems. Experimental design can be seen in Figure 1.

2.4. Statistical Analysis. The assumption of normal data distribution was assessed by Shapiro-Wilk's test and visual inspection of their histograms and normal Q-Q plots. The assumption of homogeneity of variances was tested by Levene's test. To determine whether there are any statistically significant differences between three or more independent groups, we used the Kruskal-Wallis $\mathrm{H}$ test with pairwise comparisons using Dunn's procedure [23] with a Bonferroni adjustment. To determine whether there are any statistically significant differences between the two groups, we used the Mann-Whitney $U$ test or the independent samples $t$-test. The measure of the strength and direction of the association between two continuous or ordinal variables was evaluated by Spearman's rank-order correlation. Those tests were carried out using SPSS Statistics version 22 (IBM Corporation, Chicago, Illinois). All statistical analyses were performed at the significance level of $\alpha=0.05$.

\section{Results}

3.1. The pH in Different Parts of the Gastrointestinal Canal. One-way ANOVA showed that the $\mathrm{pH}$ of a mouth cavity significantly differs between treatment groups $(p=0.009)$. Tukey's post hoc test revealed that the $\mathrm{pH}$ of the mouth cavity in CoG $(7.9 \pm 0.25)$ was significantly lower than in the PreG $(8.6 \pm 0.35)$, and the $\mathrm{pH}$ in SynG $(7.6 \pm 0.21)$ was significantly lower than in Pre12. The $\mathrm{pH}$ of rumen atrium ruminis in CoG $(7.1 \pm 0.12)$ was significantly higher than in SynG (4.7 \pm 0.15$)$, and it was significantly higher in PreG $(7.5 \pm 0.85)$ than in SynG. The $\mathrm{pH}$ of rumen ventral sac in both CoG $(7.1 \pm 0.10)$ and PreG (7.5 \pm 0.60$)$ was significantly higher than in SynG $(4.8 \pm 0.30)$. The $\mathrm{pH}$ of the middle part of the abomasum in CoG $(2.1 \pm 0.25)$ was significantly lower than in PreG (3.8 \pm 0.70$)$, but, in SynG $(2.0 \pm 0.35)$, it was significantly lower than in PreG. The $\mathrm{pH}$ of the middle part of the colon in both CoG $(6.0 \pm 0.12)$ and PreG $(6.5 \pm 0.38)$ was significantly higher than in SynG $(5.3 \pm 0.15)$ (Table 1$)$.

3.2. Morphometric Parameters of Stomach. In addition, there were no significant differences between the weight and relative weight of all forestomachs, abomasum, and whole stomach between both groups, $p>0.05$ (Table 2).

The percentual volume of abomasum was $16.2 \%$ in CoG, $14.6 \%$ in PreG, and $19.8 \%$ in SynG, but the percentual volume of forestomachs was $83.8 \%$ in CoG, $85.4 \%$ in PreG, and $80.2 \%$ in SynG; however, these differences were not significant $p>0.05$.

3.3. Histological Examination of Rumen. We observed significant differences between papillae length and width, the thickness of the ruminal epithelium, and the thickness of stratum corneum of rumen saccus dorsalis as well as between the length of papillae, the thickness of the ruminal epithelium, and the thickness of stratum corneum of rumen saccus ventralis (Table 3 ).

The mucosa of the abomasum in the cardia zone was significantly thicker in the synbiotic group and prebiotic group than in the control group. In the CoG group, the thickness of abomasum in the cardia zone was $\mathrm{Me}=510$ (IQR 472-558) $\mu \mathrm{m}, \mathrm{Me}=571$ (IQR 571) $\mu \mathrm{m}$ in PreG, and $\mathrm{Me}=610$ (IQR 585-642) $\mu \mathrm{m}$ in the SynG group, $p<0.001$, but the thickness of mucosa in fundus zone in SynG $\mathrm{Me}=673(\mathrm{IQR} 632-752) \mu \mathrm{m}$ was significantly thicker than in $\mathrm{CoG} \mathrm{Me}=581$ (IQR 515-657) $\mu \mathrm{m}$ and in PreG $\mathrm{Me}=620$ (IQR 575-660) $\mu \mathrm{m}, p<0.001$. The thickness of mucosa of abomasum in the pyloric gland zone in PreG Me $=912$ (IQR 852-1100) $\mu \mathrm{m}$ was significantly thicker than in both CoG $\mathrm{Me}=834 \quad(\mathrm{IQR}$ 787-896) and SynG $\mathrm{Me}=854 \quad(\mathrm{IQR}$ 792-900), $p<0.001$.

3.4. Histological Examination of Small and Large Intestine. There were significant differences between all treatment groups in such parameters as the thickness of the mucosa of the middle part of the duodenum, the end of the jejunum, and the thickness of the whole wall in the end of the jejunum. The other parameters significantly differed between the groups (Table 4).

\section{Discussion}

Prebiotic inulin and our novel synbiotic (prebiotic inulin and yeast Saccharomyces cerevisiae strain 1026) had a significant impact on $\mathrm{pH}$ in different parts of the gastrointestinal canal in calves and significantly improved the development of its different microscopic structures but did not affect the weight and relative weight of different parts of the stomach.

Prebiotics and probiotics can impact the $\mathrm{pH}$ in the whole gastrointestinal canal. Krol [24] tested a prebiotic mannan oligosaccharide (MOS) at the dose of $4 \mathrm{~g} /$ day/head and documented that it significantly increased rumen $\mathrm{pH}$ compared to the group of calves which did not receive this 


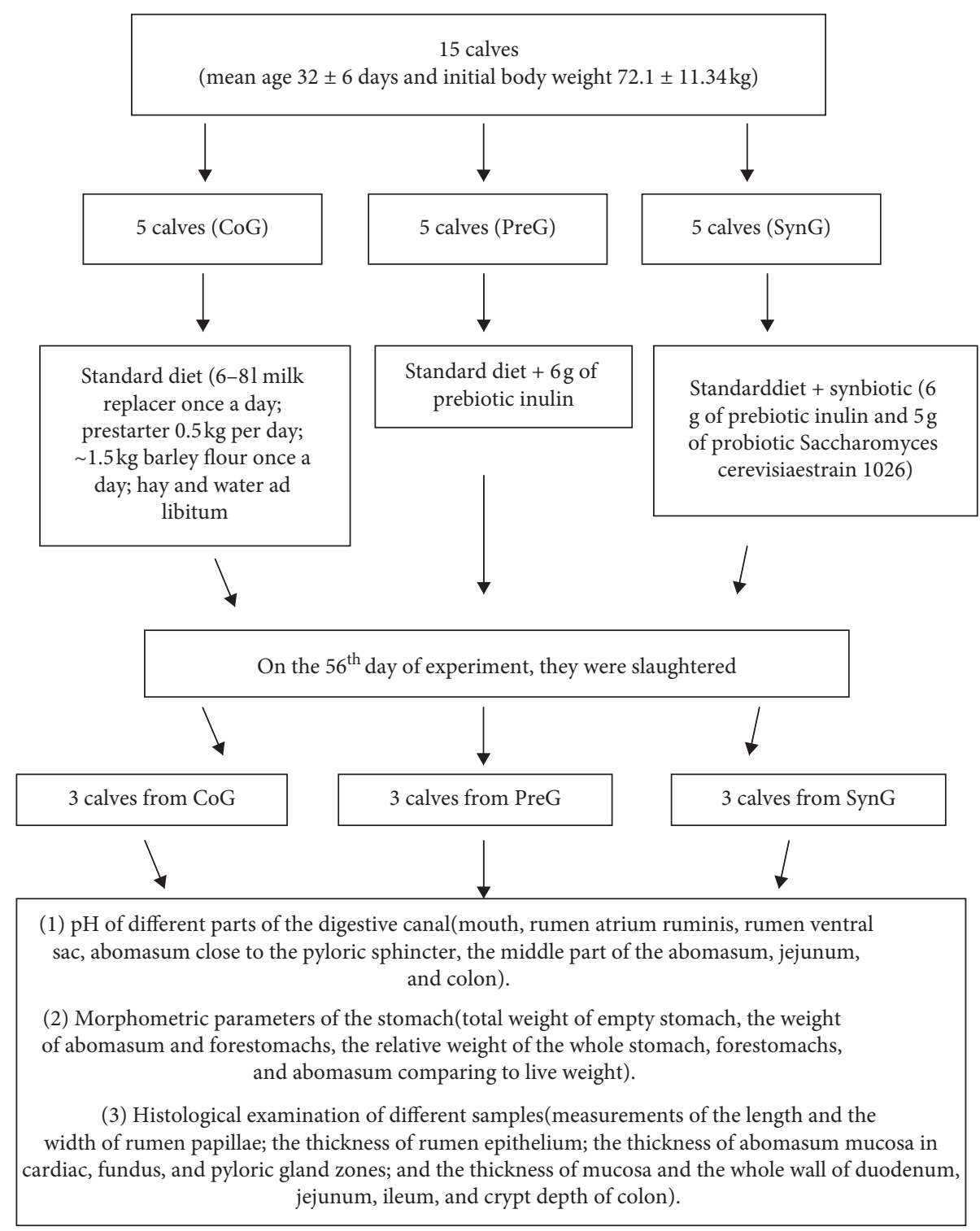

FIGURE 1: Full experimental design.

TABle 1: The $\mathrm{pH}$ in different parts of the gastrointestinal canal.

\begin{tabular}{|c|c|c|c|c|}
\hline \multirow{2}{*}{ Place of measurement } & \multicolumn{3}{|c|}{$\mathrm{pH}($ mean $\pm \mathrm{SD})$} & \multirow{2}{*}{$p$ value ANOVA } \\
\hline & CoG & PreG & SynG & \\
\hline Mouth cavity & $7.9 \pm 0.25^{\mathrm{ac}}$ & $8.6 \pm 0.35^{\mathrm{b}}$ & $7.6 \pm 0.21^{\mathrm{c}}$ & 0.009 \\
\hline Rumen atrium ruminis & $7.1 \pm 0.12^{\mathrm{ab}}$ & $7.5 \pm 0.85^{\mathrm{b}}$ & $4.7 \pm 0.15^{\mathrm{c}}$ & 0.001 \\
\hline Rumen ventral sac & $7.1 \pm 0.10^{\mathrm{ab}}$ & $7.5 \pm 0.60^{\mathrm{b}}$ & $4.8 \pm 0.30^{c}$ & $<0.001$ \\
\hline Abomasum close to the pyloric sphincter & $2.7 \pm 1.07$ & $3.6 \pm 0.35$ & $2.1 \pm 0.51$ & 0.092 \\
\hline Middle part of the abomasum & $2.1 \pm 0.25^{\mathrm{ac}}$ & $3.8 \pm 0.70^{\mathrm{b}}$ & $2.0 \pm 0.35^{\mathrm{c}}$ & 0.007 \\
\hline Middle part of jejunum & $6.3 \pm 0.15$ & $7.0 \pm 0.70$ & $6.0 \pm 0.06$ & 0.070 \\
\hline Middle part of colon & $6.0 \pm 0.12^{\mathrm{ab}}$ & $6.5 \pm 0.38^{\mathrm{b}}$ & $5.3 \pm 0.15^{\mathrm{c}}$ & 0.003 \\
\hline
\end{tabular}

${ }^{\mathrm{a}-\mathrm{c}}$ Means within a row without common superscripts are significantly different $(p<0.05)$. SD = standard deviation; CoG = control group; PreG = prebiotic group; SynG = synbiotic group.

prebiotic. He also tested prebiotic inulin in amounts of 3 and $6 \mathrm{~g} /$ day/head and documented similar results. Our results are in accordance with those of Krol [24]; we also documented higher rumen $\mathrm{pH}$ in calves which received prebiotic inulin compared to the control group.
Yeast $S$. cerevisiae uses oxygen creating a more anaerobic environment required by ruminal microorganisms and stimulates their growth, thereby indirectly stabilizing ruminal $\mathrm{pH}[25,26]$. Therefore, the yeast itself not only functions as a probiotic but also helps other rumen 
TABLE 2: Weight $(\mathrm{kg})$ and relative weight of different parts of the stomach (\% of body weight).

\begin{tabular}{lcccc}
\hline Parameter $(\mathrm{kg})($ mean \pm SD) & CoG & PreG & SynG & $p$ value \\
\hline Whole stomach & $3.9 \pm 0.53$ & $4.4 \pm 0.4$ & $3.6 \pm 0.22$ & 0.525 \\
Forestomachs & $3.2 \pm 0.39$ & $3.7 \pm 0.3$ & 0.830 \\
Abomasum & $0.6 \pm 0.14$ & $0.6 \pm 0.1$ & $0.7 \pm 0.16$ & 0.423 \\
\hline Parameter (\% of body weight) (mean \pm SD) & & & & \\
Whole stomach & $3.5 \pm 1.17$ & $3.4 \pm 0.23$ & $3.0 \pm 0.37$ & 0.505 \\
Forestomachs & $2.9 \pm 0.93$ & $2.9 \pm 0.19$ & $2.4 \pm 0.47$ & 0.669 \\
Abomasum & $0.6 \pm 0.25$ & $0.5 \pm 0.04$ & $0.6 \pm 0.10$ & 0.412 \\
\hline
\end{tabular}

$\mathrm{SD}=$ standard deviation; $\mathrm{CoG}=$ control group; $\mathrm{PreG}=$ prebiotic group; $\mathrm{SynG}=$ synbiotic group .

TABLE 3: Results of histological examination of the rumen.

\begin{tabular}{|c|c|c|c|c|c|c|c|c|}
\hline \multirow{2}{*}{ Localization } & \multirow{2}{*}{ Parameters $(\mu \mathrm{m})$} & \multicolumn{2}{|c|}{$\mathrm{CoG}$} & \multicolumn{2}{|c|}{ PreG } & \multicolumn{2}{|c|}{ SynG } & \multirow{2}{*}{$\begin{array}{l}p \text { value } \mathrm{K}-\mathrm{W} \\
\text { test }\end{array}$} \\
\hline & & Median & Q1-Q3 & Median & Q1-Q3 & Median & Q1-Q3 & \\
\hline \multirow{4}{*}{$\begin{array}{l}\text { Rumen saccus } \\
\text { dorsalis }\end{array}$} & The length of papillae & $1016^{\mathrm{ac}}$ & $765-1692$ & $899^{\mathrm{b}}$ & $668-1098$ & $1033^{\mathrm{c}}$ & $764-1525$ & 0.004 \\
\hline & The width of papillae & $282^{\mathrm{a}}$ & $246-341$ & $344^{\mathrm{bc}}$ & $312-431$ & $371^{\mathrm{c}}$ & $310-475$ & $<0.001$ \\
\hline & $\begin{array}{c}\text { The thickness of ruminal } \\
\text { epithelium }\end{array}$ & $77^{\mathrm{a}}$ & $66-86$ & $122^{\mathrm{b}}$ & $101-171$ & $153^{\mathrm{c}}$ & $123-176$ & $<0.001$ \\
\hline & $\begin{array}{c}\text { The thickness of stratum } \\
\text { corneum }\end{array}$ & $9^{\mathrm{a}}$ & $7-12$ & $17^{\mathrm{b}}$ & $14-22$ & $33^{c}$ & $24-38$ & $<0.001$ \\
\hline \multirow{4}{*}{$\begin{array}{l}\text { Rumen saccus } \\
\text { ventralis }\end{array}$} & The length of papillae & $1113^{\mathrm{ab}}$ & $850-1578$ & $1359^{\mathrm{b}}$ & $831-2036$ & $1647^{\mathrm{c}}$ & $1304-2203$ & $<0.001$ \\
\hline & The width of papillae & 334 & $275-395$ & 346 & $270-413$ & 322 & $287-377$ & 0.861 \\
\hline & $\begin{array}{c}\text { The thickness of ruminal } \\
\text { epithelium }\end{array}$ & $97^{\mathrm{a}}$ & $72-127$ & $129^{b c}$ & 99-177 & $120^{\mathrm{c}}$ & $102-164$ & $<0.001$ \\
\hline & $\begin{array}{l}\text { The thickness of stratum } \\
\text { corneum }\end{array}$ & $9^{\mathrm{a}}$ & $7-12$ & $25^{\mathrm{bc}}$ & $15-32$ & $29^{c}$ & $24-36$ & $<0.001$ \\
\hline
\end{tabular}

${ }^{a-c}$ Means within a row without common superscripts are significantly different $(p<0.05)$ Q1-Q3=Quatile 1-Quartile 3; CoG=control group; PreG = prebiotic group; SynG = synbiotic group .

TABLE 4: Results of histological examination of intestines.

\begin{tabular}{|c|c|c|c|c|c|c|c|c|}
\hline \multirow{3}{*}{ Localization } & \multirow{3}{*}{ Parameters $(\mu \mathrm{m})$} & \multicolumn{6}{|c|}{ Group } & \multirow{3}{*}{$\begin{array}{c}p \text { value } \mathrm{K}-\mathrm{W} \\
\text { test }\end{array}$} \\
\hline & & \multicolumn{2}{|c|}{ CoG } & \multicolumn{2}{|c|}{ PreG } & \multicolumn{2}{|c|}{ SynG } & \\
\hline & & Median & Q1-Q3 & Median & Q1-Q3 & Median & Q1-Q3 & \\
\hline \multirow{2}{*}{$\begin{array}{l}\text { The middle part of the } \\
\text { duodenum }\end{array}$} & $\begin{array}{l}\text { The thickness of mucosa } \\
\text { (villi + crypts) }\end{array}$ & 917 & 799-1066 & 929 & 819-1093 & 952 & 874-1048 & 0.628 \\
\hline & $\begin{array}{l}\text { The thickness of the whole } \\
\text { wall }\end{array}$ & $1595^{\mathrm{a}}$ & $1513-1665$ & $1981^{b c}$ & $1800-2029$ & $2042^{c}$ & $1922-2125$ & $<0.001$ \\
\hline \multirow{2}{*}{$\begin{array}{l}\text { The middle part of the } \\
\text { jejunum }\end{array}$} & $\begin{array}{l}\text { The thickness of mucosa } \\
\text { (villi + crypts) }\end{array}$ & $1647^{\mathrm{a}}$ & $1157-2320$ & $2234^{\mathrm{bc}}$ & $1740-2455$ & $234^{6 c}$ & $1815-2635$ & $<0.001$ \\
\hline & $\begin{array}{l}\text { The thickness of the whole } \\
\text { wall }\end{array}$ & $2412^{\mathrm{a}}$ & $1931-2858$ & $3154^{\mathrm{bc}}$ & $2967-3550$ & $3197^{c}$ & $2935-3579$ & $<0.001$ \\
\hline \multirow{2}{*}{$\begin{array}{l}\text { The end part of the } \\
\text { jejunum }\end{array}$} & $\begin{array}{l}\text { The thickness of mucosa } \\
\text { (villi + crypts) }\end{array}$ & 1216 & $1147-1414$ & 1193 & $1079-1363$ & 1211 & $1107-1326$ & 0.641 \\
\hline & $\begin{array}{l}\text { The thickness of the whole } \\
\text { wall }\end{array}$ & 1907 & $1758-4199$ & 2162 & $1922-2728$ & 2580 & $2258-3111$ & 0.165 \\
\hline \multirow{2}{*}{$\begin{array}{l}\text { The middle part of the } \\
\text { ileum }\end{array}$} & $\begin{array}{l}\text { The thickness of mucosa } \\
\text { (villi + crypts) }\end{array}$ & $1632^{\mathrm{a}}$ & $1559-1777$ & $2983^{\mathrm{bc}}$ & $2413-3581$ & $2889^{c}$ & $1743-3259$ & $<0.001$ \\
\hline & $\begin{array}{l}\text { The thickness of the whole } \\
\text { wall }\end{array}$ & $969^{\mathrm{ac}}$ & $895-1023$ & $1601^{\mathrm{b}}$ & $1403-1855$ & $1073^{c}$ & $953-1217$ & $<0.001$ \\
\hline \multirow{2}{*}{$\begin{array}{l}\text { The middle part of the } \\
\text { colon }\end{array}$} & The crypt depth & $612^{\mathrm{ab}}$ & $566-671$ & $659^{\mathrm{b}}$ & $618-721$ & $764^{\mathrm{c}}$ & $729-799$ & $<0.001$ \\
\hline & $\begin{array}{l}\text { The thickness of the whole } \\
\text { wall }\end{array}$ & $1371^{\mathrm{ab}}$ & $1232-1481$ & $1325^{\mathrm{b}}$ & $1280-1423$ & $1758^{\mathrm{c}}$ & $1665-1935$ & $<0.001$ \\
\hline
\end{tabular}

\footnotetext{
${ }^{\mathrm{a}-\mathrm{c}}$ Means within a row without common superscripts are significantly different $(p<0.05)$ Q1-Q3=Quatile $1-\mathrm{Quartile} 3$; CoG=control group; PreG = prebiotic group; SynG = synbiotic group.
} 
community members grow, and, thus, acts as a type of prebiotic. Yeast S. cerevisiae also reduces the availability of glucose which is needed for S.bovis to synthesize lactate and increases the utilization of l-lactate by M. elsdenii [27]. Ishaq et al. [28] fed active dry yeast to the dairy cows and recorded an increase in $\mathrm{pH}$ and rumen protozoal abundance. The increase in rumen $\mathrm{pH}$ could also be explained by partial defaunation of the rumen ecosystem as a result of brewer's yeast addition [29]. Specific yeast product Yea-Sacc 1026 increases the microbiologic activity of rumen via nitrogen metabolism changes in the rumen (reduction of ammonium concentration) [30], but hydrolyzed yeast stimulates proliferation of rumen bacteria $[31,32]$.

We have documented lower rumen $\mathrm{pH}$ in calves which received an additional supplement of synbiotic (inulin and S. cerevisiae strain 1026) to their diet when compared to the control group and the prebiotic group. These results are contrary to all study results described above, suggesting that yeast in combination with inulin does not increase rumen $\mathrm{pH}$.

Probiotics not only positively impact rumen but also can enhance intestinal health. These additives stimulate the development of a healthy microbiota, prevent enteric pathogens from colonizing the intestine, increase digestive capacity, lower the $\mathrm{pH}$, and improve mucosal immunity [33].

In the study reported by Tzortzis et al. [34], prebiotic inulin at the dose of $40 \mathrm{~g} / \mathrm{kg}$ added to pigs' feed for 33-35 days caused a significant increase in Bifidobacterium count, increase in acetic acid level, and reduction in intestinal $\mathrm{pH}$, compared to the control group. The observation was in agreement with the results reported by Júskiewicz et al. [35]. These authors observed the reduction in the intestinal $\mathrm{pH}$ in turkeys administered fructooligosaccharides (FOS) for 8 weeks at a concentration of $2 \%$. These results are contrary to ours. We documented slightly higher $\mathrm{pH}$ in jejunum and colon compared to the control group, but we observed the reduction of $\mathrm{pH}$ in jejunum and colon in calves supplemented with synbiotic; the difference of $\mathrm{pH}$ in the colon in the synbiotic group significantly differed from the control group.

There is ambiguous information about the effect of $S$. cerevisiae yeast on the structural and functional development of the rumen. Supplementation of the yeast culture at $2 \%$ in a 42 -day- long study slightly improves rumen development in calves [36]. In this experiment, the authors recorded an increase in papillae length and width at the time of weaning off, but this increase was not significant. Brewer et al. [37] in his 5-week long experiment found that S. cerevisiae fermentation products at the dosage of $1 \mathrm{~g} / \mathrm{head} /$ day and $3.5 \mathrm{~g} / \mathrm{head} /$ day enhance ruminal papilla length and width in calves. This observation was in agreement with the results reported by Xiao et al. [11] who performed 52-day long experiment by using S. cerevisiae fermentation products at the dosage of $0.5 \%$ and $1 \%$. Besides, the authors documented the reduction of crypt depth of jejunum in calves supplemented with $S$. cerevisiae fermentation product.

Interesting results were observed in experiments with sheep. In examination with adding $S$. cerevisiae $2 \mathrm{~g} / \mathrm{kg}$ dry matter (DM), MOS, $2 \mathrm{~g} / \mathrm{kg} \mathrm{DM}$, and combination of this yeast and MOS (2g/kg DM of S. cerevisiae $+2 \mathrm{~g} / \mathrm{kg}$ DM of MOS) to sheep diet for 42 days revealed that the synbiotic treatment group had thinner stratum corneum in rumen compared to the control group. The total thickness of ruminal epithelium was lower in the group of sheep which received MOS than in a group of sheep which received S. cerevisiae additive. The thickness of stratum corneum was increased in the control group and in the S. cerevisiae group compared with the MOS and synbiotic groups, but these additives did not influence the widths of the papillae [38].

We documented a significant increase in the width of papillae in rumen saccus dorsalis and a significant increase in the length of papillae in rumen saccus ventralis in the synbiotic group compared to the control group. However, the prebiotic group showed better results in both the length of papillae and the width of papillae in rumen saccus dorsalis, but no significant differences in these parameters in rumen saccus ventralis when compared to the control group. We documented that the length of papillae in rumen saccus dorsalis and in rumen saccus ventralis was significantly greater in the synbiotic group than in the group which received just prebiotic inulin suggesting that the addition of yeast $S$. cerevisiae to inulin could potentially increase the rate of rumen papillae development. The thickness of the ruminal epithelium and stratum corneum in rumen saccus dorsalis and ventralis was significantly lower in calves of the control group compared to the group of calves receiving a combination of prebiotic inulin and probiotic S. cerevisiae strain 1026 and single prebiotic inulin. Our results are contrary to those of Magalhães et al. [39]; these authors observed no effect of yeast culture ( $2 \%$ of DM) on rumen development and function in a 70-day long experiment. Similar results are reported by Kaldmae et al. [40]. The authors observed no differences in calves' papillae length and width, rumen wall thickness at either one or two months of age when supplemented with S. cerevisiae ( $2 \%$ of DM) for 2 months.

There is very little information about the impact of $S$. cerevisiae yeast on hindgut digestion in ruminants. It could be because it is thought that yeast culture functions mainly in the rumen. In the study with lambs, DurandChaucheyras et al. [41] found that yeast cells remain alive in hindgut, suggesting that effects of yeast may be seen in different parts of the gastrointestinal canal, not just rumen. These results are in agreement with the results reported by Xiao et al. [11]. The authors found a significant increase in villus height of duodenum, jejunum, and ileum and a decrease in crypt depth of all parts of the small intestine in calves receiving $S$. cerevisiae fermentation products in doses $0.5 \%$ and $1 \%$ of DM for 52 days. Similar results were observed in research with piglets. The authors claimed that dietary supplementation of $S$. cerevisiae fermentation products ( $5 \mathrm{~g} / \mathrm{kg}$ for 21 days) resulted in greater jejunal villus height compared with the control group in piglets [42]. Saccharomyces cerevisiae fermentation product $(2.5 \mathrm{~g} / \mathrm{kg}$ for 42 days) improved villus height in duodenum and jejunum, a crypt depth in duodenum, jejunum, and ileum in broilers [43]. These results are in agreement with those of our experiments. We noticed significant differences between 
synbiotic and control groups in such parameters as the thickness of the whole wall of the middle part of duodenum, jejunum, ileum, and colon and the thickness of mucosa (villi height and crypt depth) of the middle part of jejunum and crypt depth in the colon. All of these parameters were significantly greater in calves of the synbiotic group. Taller villi indicate more mature epithelium and enhanced absorptive function due to the increased absorptive area of the villus. Greater villus height increases the activities of enzymes secreted from the tips of the villi, resulting in improved digestibility [44].

There are several studies about the impact of prebiotic inulin on intestinal morphological changes. Masanetz et al. [45] reported that jejunum and ileum villus was shorter in 20-week long experiments with calves which received prebiotic $2 \%$ inulin, but villus in $2 \%$ lactulose treated animals was longer compared to the control group. These results are in agreement with those reported by Pierce et al. [46]. They reported a similar decrease of villus length after the addition of inulin $(15 \mathrm{~g} / \mathrm{kg})$ to the feed of weaning piglets for 28 days. However, Rehman et al. [47] implied that inulin has a positive impact on intestine. These authors conducted a study with broiler chickens and found that $1 \%$ inulin in a 5week long trial significantly increases the length of jejunum villi and results in deeper crypts in the inulin group. Our results are in agreement with Rehman et al. [47]. We recorded that the thickness of the whole wall (villi + crypts) in the middle part of duodenum, jejunum, and ileum as well as the thickness of mucosa in the middle part of jejunum and ileum was significantly greater in the prebiotic group than in the control group. The positive effect of prebiotics on small and large intestine mucosal growth and development could be explained by the synthesis of polyamines from prebiotics which are essential for intestinal development [48] or by the fermentation of inulin that provided short-chain fatty acids. These acids can also promote the proliferation of cells of the large and small intestine and, as a result, increase villus height and crypt depth [49].

\section{Conclusion}

We concluded that prebiotic inulin $(6 \mathrm{~g}$ per head) and our novel synbiotic (6g prebiotic inulin and $5 \mathrm{~g}$ yeast Saccharomyces cerevisiae strain 1026) impact $\mathrm{pH}$ in different parts of the gastrointestinal canal in calves. The addition of prebiotic inulin to calves' diet causes the increase of $\mathrm{pH}$ in rumen, abomasum, and intestines but when inulin was added to $S$. cerevisiae, $\mathrm{pH}$ decreased and was even lower than in the control group. Prebiotic inulin and its synbiotic with yeast $S$. cerevisiae positively impact the development of almost all morphological structures of rumen saccus dorsalis, rumen saccus ventralis, and intestine; moreover, calves from the synbiotic group showed better results in virtually all parameters. However, both inulin and synbiotic did not affect the weight and relative weight of different parts of the stomach. As the results of our study are very promising but the significance of these results was not always clear, we suggest continuing this research with an increased number of examined animals to confirm our findings.

\section{Data Availability}

The data used to support the findings of this study are available from the corresponding author upon request.

\section{Conflicts of Interest}

The authors declare that there are no conflicts of interest regarding the publication of this paper.

\section{Acknowledgments}

This research has been supported by the National Research Program, Agricultural Resources for Sustainable Production of Qualitative and Healthy Foods in Latvia (AgroBioRes), Project no. 3 LIVESTOCK (VPP-20142018).

\section{References}

[1] C. L. Davis and J. K. Drackley, The Development, Nutrition, and Management of the Young Calf, Iowa State University Press, Iowa, IA, USA, 1st edition, 1998.

[2] J. I. Longenbach and A. J. Heinrichs, "A review of the importance and physiological role of curd formation in the abomasum of young calves," Animal Feed Science and Technology, vol. 73, no. 1, pp. 85-97, 1998.

[3] K. Govil, D. S. Yadav, A. K. Patil et al., "Feeding management for early rumen development in calves," Journal of Entomology and Zoology Studies, vol. 5, no. 3, pp. 1132-1139, 2017.

[4] R. L. Baldwin, K. R. McLeod, J. L. Klotz, and R. N. Heitmann, "Rumen development, intestinal growth and hepatic metabolism in the pre- and postweaning ruminant," Journal of Dairy Science, vol. 87, pp. E55-E65, 2004.

[5] K. E. Lesmeister, P. R. Tozer, and A. J. Heinrichs, "Development and analysis of a rumen tissue sampling procedure," Journal of Dairy Science, vol. 87, no. 5, pp. 1336-1344, 2004 b.

[6] G. R. Gibson, K. P. Scott, R. A. Rastall et al., "Dietary prebiotics: current status and new definition," Food Science \& Technology Bulletin: Functional Foods, vol. 7, no. 1, pp. 1-19, 2010.

[7] C. R. Krehbiel, S. R. Rust, G. Zhang, and S. E. Gilliland, "Bacterial direct-fed microbials in ruminant diets: performance response and mode of action," Journal of Animal Science, vol. 81, no. 2, pp. E120-E132, 2003.

[8] H. A. Hong, L. H. Duc, and S. M. Cutting, "The use of bacterial spore formers as probiotics: table 1," FEMS Microbiology Reviews, vol. 29, no. 4, pp. 813-835, 2005.

[9] G. Ding, Y. Chang, L. Zhao, Z. Zhou, L. Ren, and Q. Meng, "Effect of Saccharomyces cerevisiae on alfalfa nutrient degradation characteristics and rumen microbial populations of steers fed diets with different concentrate-to-forage ratios," Journal of Animal Science and Biotechnology, vol. 5, no. 1, pp. 1-24, 2014.

[10] U. Kumar, V. K. Sareen, and S. Singh, "Effect of Saccharomyces cerevisiae yeast culture supplement on ruminal metabolism in buffalo calves given a high concentrate diet," Animal Science, vol. 59, no. 2, pp. 209-215, 1994.

[11] J. X. Xiao, G. M. Alugongo, R. Chung et al., "Effects of Saccharomyces cerevisiae fermentation products on dairy calves: ruminal fermentation, gastrointestinal morphology, and microbial community," Journal of Dairy Science, vol. 99, no. 7, pp. 5401-5412, 2016. 
[12] F. Chaucheyras-Durand, N. D. Walker, and A. Bach, "Effects of active dry yeasts on the rumen microbial ecosystem: past, present and future," Animal Feed Science and Technology, vol. 145, no. 1-4, pp. 5-26, 2008.

[13] H. Hardy, J. Harris, E. Lyon, J. Beal, and A. Foey, "Probiotics, prebiotics and immunomodulation of gut mucosal defences: homeostasis and immunopathology," Nutrients, vol. 5, no. 6, pp. 1869-1912, 2013.

[14] S. Patel and A. Goyal, "The current trends and future perspectives of prebiotics research: a review," 3 Biotech, vol. 2, no. 2, pp. 115-125, 2012.

[15] T. Mizota, T. Mori, T. Yaeshima et al., "Effects of low dosages of lactulose on the intestinal function of healthy adults," Milchwissenschaft, vol. 57, no. 6, pp. 312-315, 2002.

[16] P. M. Roodposhti and N. Dabiri, "Effects of probiotic and prebiotic on average daily gain, fecal shedding of Escherichia coli, and immune system status in newborn female calves," Asian-Australasian Journal of Animal Sciences, vol. 25, no. 9, pp. 1255-1261, 2012.

[17] G. R. Gibson, E. R. Beatty, X. Wang, and J. H. Cummings, "Selective stimulation of Bifidobacteria in the human colon by oligofructose and inulin," Gastroenterology, vol. 108, no. 4, pp. 975-982, 1995.

[18] B. Kleesen, C. Hartmann, and M. Blaut, "Oligofructose and long-chain inulin: influence on the gut microbial ecology of rats associated with human faecal flora," The British Journal of Nutrition, vol. 86, no. 2, pp. 291-300, 2001.

[19] G. R. Gibson and M. B. Roberfroid, "Dietary modulation of the human colonic microbiota: introducing the concept of prebiotics," The Journal of Nutrition, vol. 125, no. 6, pp. 1401-1412, 1995.

[20] K. R. Niness, "Inulin and oligofructose: what are they?" The Journal of Nutrition, vol. 129, no. 7, pp. 1402S-1406S, 1999.

[21] K. S. Swanson, G. R. Gibson, R. Hutkins et al., "The International Scientific Association for Probiotics and Prebiotics (ISAPP) consensus statement on the definition and scope of synbiotics," Nature Reviews Gastroenterology \& Hepatology, vol. 17, no. 11, pp. 687-701, 2020.

[22] M. B. Roberfroid, "Prebiotics and synbiotics: concepts and nutritional properties," The British Journal of Nutrition, vol. 80, no. 4, pp. 197-202, 1998.

[23] O. J. Dunn, "Multiple comparisons using rank sums," Technometrics, vol. 6, no. 3, pp. 241-252, 1964.

[24] B. Krol, "Effect of mannan oligosaccharides, inulin and yeast nucleotides added to calf milk replacer on rumen microflora, level of serum immunoglobulin and health condition of calves," Electronic Journal of Polish Agricultural Universities, vol. 14, no. 2, pp. 1-18, 2011.

[25] P. McDonald, R. A. Edwards, J. F. D. Greenhalgh, C. A. Morgan, L. A. Sinclair, and R. G. Wilkinson, "Food additives," in Animal Nutrition, J. F. D. Greenhalgh, C. A. Morgan, L. A. Sinclair, and R. G. Wilkinson, Eds., pp. 594-607, Pearson Education Ltd., London, UK, 7th edition, 2011.

[26] B. A. Dehority, "Numbers, factors affecting the population and distribution of rumen bacteria," in Rumen Microbiology, B. A. Dehority, Ed., pp. 265-294, Universities Press, Nottingham, UK, 2003.

[27] F. Chaucheyras, G. Fonty, P. Gouet, G. Bertin, and J.-M. Salmon, "Effects of a strain of Saccharomyces cerevisiae (Levucell SC), a microbial additive for ruminants, on lactate metabolism in vitro," Canadian Journal of Microbiology, vol. 42, no. 9, pp. 927-933, 1996.
[28] S. L. Ishaq, O. AlZahal, N. Wlker, and B. McBride, "An investigation into rumen fungal and protozoal diversity in the three rumen fractions, during high fiber or grain-induced subacute acidosis conditions, with or without active dry yeast supplementation," Frontiers in Microbiology, vol. 8, no. 10, p. 1943, 2017.

[29] K. M. Koenig, C. J. Newbold, F. M. McIntosh, and L. M. Rode, "Effects of protozoa on bacterial nitrogen recycling in the rumen," Journal of Animal Science, vol. 78, no. 9, pp. 2431-2445, 2000.

[30] K. A. Dawson, "Designing the yeast culture oftomorrow: mode of action of yeast culture for ruminants and non-ruminants," in Biotechnology in the Feed Industry. Nicholasville, T. P. Lyons, Ed., pp. 59-78, Alltech Technical Publications, Nicholasville, KY, USA, 1990.

[31] F. Chaucheyras, G. Fonty, G. Bertin, and P. Gouet, "In vitro $\mathrm{H} 2$ utilization by a ruminal acetogenic bacterium cultivated alone or in association with an archaea methanogen is stimulated by a probiotic strain of Saccharomyces cerevisiae," Applied and Environmental Microbiology, vol. 61, no. 9, pp. 3466-3467, 1995.

[32] D. J. Nisbet and S. A. Martin, "Effect of a Saccharomyces cerevisiae culture on lactate utilization by the ruminal bacterium Selenomonas ruminantium," Journal of Animal Science, vol. 69, no. 11, pp. 4628-4633, 1991.

[33] Y. Uyeno, S. Shigemori, and T. Shimosato, "Effect of probiotics/prebiotics on cattle health and productivity," Microbes and Environments, vol. 30, no. 2, pp. 126-132, 2015.

[34] G. Tzortzis, A. K. Goulas, J. M. Gee, and G. R. Gibson, “A novel galactooligosaccharide mixture increases the bifidobacterial population numbers in a continuous in vitro fermentation system and in the proximal colonic contents of pigs in vivo," The Journal of Nutrition, vol. 135, no. 7, pp. 1726-1731, 2005.

[35] J. Júskiewicz, J. Jankowski, Z. Zduńczyk, and D. Mikulski, "Performance and gastrointestinal tract metabolism of turkeys fed diets with different contents of fructooligosaccharides," Poultry Science, vol. 85, no. 5, pp. 886-891, 2006.

[36] K. E. Lesmeister, A. J. Heinrichs, and M. T. Gabler, "Effects of supplemental yeast (Saccharomyces cerevisiae) culture on rumen development, growth characteristics, and blood parameters in neonatal dairy calves," Journal of Dairy Science, vol. 87 , no. 6, pp. 1832-1839, 2004a.

[37] M. T. Brewer, K. L. Anderson, I. Yoon, M. F. Scott, and S. A. Carlson, "Amelioration of salmonellosis in pre-weaned dairy calves fed Saccharomyces cerevisiae fermentation products in feed and milk replacer," Veterinary Microbiology, vol. 172, no. 1-2, pp. 248-255, 2014.

[38] T. G. Diaz, A. F. Branco, F. A. Jacovaci, C. C. Jobim, D. C. Bolson, and J. L. P. Daniel, "Inclusion of live yeast and mannan-oligosaccharides in high grain-based diets for sheep: ruminal parameters, inflammatory response and rumen morphology," PLoS One, vol. 13, no. 2, Article ID e0193313, 2018.

[39] V. J. A. Magalhães, F. Susca, F. S. Lima, A. F. Branco, I. Yoon, and J. E. P. Santos, "Effect of feeding yeast culture on performance, health, and immunocompetence of dairy calves," Journal of Dairy Science, vol. 91, no. 4, pp. 1497-1509, 2008.

[40] H. Kaldmae, H. Suurmets, T. Jarveots, T. Suuroja, and O. Kart, "Effects of supplemental yeast (Saccharomyces cerevisiae) culture on rumen development and growth in calves," Akadeemiline Pollumajanduse Selts, vol. 19, no. 1, pp. 19-23, 2004.

[41] F. Durand-Chaucheyras, G. Fonty, G. Bertin, M. Théveniot, and P. Gouet, "Fate of Levucell SC I-1077 yeast additive 
during digestive transit in lambs," Reproduction Nutrition Development, vol. 38, no. 3, pp. 275-280, 1998.

[42] Y. B. Shen, X. S. Piao, S. W. Kim et al., "Effects of yeast culture supplementation on growth performance, intestinal health, and immune response of nursery pigs1," Journal of Animal Science, vol. 87, no. 8, pp. 2614-2624, 2009.

[43] J. Gao, H. J. Zhang, S. H. Yu et al., "Effects of yeast culture in broiler diets on performance and immunomodulatory functions," Poultry Science, vol. 87, no. 7, pp. 1377-1384, 2008.

[44] C. J. Newbold, R. J. Wallace, and F. M. McIntosh, "Mode of action of the yeastSaccharomyces cerevisiaeas a feed additive for ruminants," British Journal of Nutrition, vol. 76, no. 2, pp. 249-261, 1996.

[45] S. Masanetz, N. Wimmer, C. Plitzner, E. Limbeck, W. Preißinger, and M. W. Pfaffl, "Effects of inulin and lactulose on the intestinal morphology of calves," Animal, vol. 4, no. 5, pp. 739-744, 2010.

[46] K. M. Pierce, T. Sweeney, P. O. Brophy, J. J. Callan, P. McCarthy, and J. V. O'Doherty, "Dietary manipulation post weaning to improve piglet performance and gastro-intestinal health,” Animal Science, vol. 81, no. 3, pp. 347-356, 2005.

[47] H. Rehman, C. Rosenkranz, J. Böhm, and J. Zentek, "Dietary inulin affects the morphology but not the sodium-dependent glucose and glutamine transport in the jejunum of broilers," Poultry Science, vol. 86, no. 1, pp. 118-122, 2007.

[48] N. M. Delzenne, N. Kok, P. Deloyer, and G. Dandrifosse, "Dietary fructans modulate polyamine concentration in the cecum of rats," The Journal of Nutrition, vol. 130, no. 10, pp. 2456-2460, 2000.

[49] L. Samal and N. C. Behura, "Prebiotics: an emerging nutritional approach for improving gut health of livestock and poultry," Asian Journal of Animal and Veterinary Advances, vol. 10, no. 11, pp. 724-739, 2015. 